\title{
Effects of pretreatment with magnesium sulphate on suxamethonium induced complications during induction of general anaesthesia-A placebo controlled study
}

\author{
Malaya Kumar Das ${ }^{1 *}$, Rubina Yasmin ${ }^{2}$, UH Shahera Khatun ${ }^{3}$, Md. Tanveer Alam ${ }^{4}$, \\ Akhtaruzzaman AKM ${ }^{5}$, Haradhan Debnath ${ }^{6}$
}

\begin{abstract}
${ }^{1}$ Burn Unit,Dhaka Medical College Hospital,Dhaka, ${ }^{2}$ National Institute of Ophthalmology and Hospital, Dhaka, ${ }^{3}$ Department of Anaesthesia Community Medical College Hospital, Dhaka, ${ }^{4}$ Anaesthesiology, Dhaka Medical College Hospital, Dhaka, ${ }^{5}$ Department of Anaesthesia, Analgesia \& Intensive Care Medicine, Bangabandhu Sheikh Mujib Medical University, Shahbag, Dhaka ${ }^{6}$ Department Of Neurosurgery, Bangabandhu Sheikh Mujib Medical University, Shahbag, Dhaka.
\end{abstract}

Corresponding Author: E-mail: dr.mahye@gmail.com

\begin{abstract}
Background To administer general anaesthesia with controlled ventilation, laryngoscopy and endotracheal intubation is necessary. Suxamethonium is drug of choice but some side effects preclude its use. Pretreatment with Magnesium sulphate reduces suxamethonium induced complications.
\end{abstract}

Objective To see the effects of pretreatment with magnesium sulphate on suxamethonium induced complications during induction of general anaesthesia.

Methods A total number of sixty patients of ASA grade I and II were selected randomly as per inclusions and exclusions criteria, thirty in each group. Group- $C$ is the control group and group-M-patients were received magnesium sulphate $60 \mathrm{mg}$ per $\mathrm{kg}$. Pulse rate, blood pressure, SPO2, ECG, Serum $\mathrm{K}^{+}$ concentration, fasciculation, myalgia and side effects of magnesium sulphate were recorded.

Results Suxamethnium induced complications like fasciculation, raised potassium concentration, haemodynamic change during intubation and post operative myalgia significantly reduced in patients pre treated with magnesium sulphate.

Conclusion Pretreatment with magnesium sulphate reduces incidence of suxamethonium induced complications during induction of general anaesthesia.

Keywords Suxamethonium, magnesium sulphate,general anaesthesia, complications.

(JBSA 2013; 26(1): 27-32)

\section{Introduction}

General anaesthesia with controlled ventilation through endotracheal tube is an anaesthetic technique used by the anaesthesiologists all over the world. laryngoscopy \& endotracheal intubation is necessary to achieve this technique. Traditionally suxamethonium is drug of choice for induction due to its rapid onset of action.

Suxamethonium induced side effects are increased serum potassium concentration, fasciculation, myalgia, arrhythmia, increased intraocular \& intragastric pressure, prolonged apnoea, and triggers malignant hyperthermia. Increased serum potassium concentration of about $0.5 \mathrm{mmol} / \mathrm{L}$ from the baseline usually do not causes too harm to the patient but in preexisting hyperkalaemia, rise of potassium level may cause life threatening situation especially arrhythmia ${ }^{1}$

Fasciculation is the result of repetitive firing of the motor nerve terminals and antidromic discharges that manifest as uncoordinated muscle contraction $^{2}$. The cause of the muscle pain is not known but it may be due to fasciculation ${ }^{1}$. Best method to avoid fasciculation is to avoid suxamethonium. To reduce incidences or prevent fasciculation and myalgia, priming with non- 
depolarizing neuromuscular blocking agents may be used.

In anaesthesia magnesium sulphate has a role in reduction of stress associated with catecholamine release during intubation. Prolongation of duration of non depolarizing neuromuscular blocking agent (mivacurium) has been reported where magnesium sulphate $\left(60 \mathrm{mg} \cdot \mathrm{kg}^{-1}\right)$ was used ${ }^{3}$. There is no prolongation of duration of depolarizing neuromuscular blocking agent pretreated with magnesium sulphate ${ }^{4}$.

Precurarization with nondepolarizing muscle relaxant is commonly used to reduce suxamethonium induced complications during induction of general endotracheal anaesthesia except for arrhythmia ${ }^{5}$.

On the other hand, magnesium sulphate $\left(\mathrm{MgSO}_{4}\right)$ has precurarization effects that reduce suxamethonium induced fasciculation ${ }^{4}$ and increases in serum potassium concentration ${ }^{6,7}$ without delay of onset and prolongation of suxamethonium induced effects. Furthermore, prior to tracheal intubation $\mathrm{MgSO}_{4}$ decreases the haemodynamic response. Pretreatment with magnesium is more effective to limit suxamethonium induced fasciculation and subsequent tracheal intubation-induced haemodynamic changes in rapid sequence induction compared with vecuronium pretreatment ${ }^{5}$. However, it causes unpleasant warm sensation for conscious patients by rapidly or slowly $\left(2 \mathrm{~min}\right.$ ) injection of $\mathrm{MgSO}_{4}{ }^{8} \cdot \mathrm{MgSO}_{4}$ administered between administration of sedatives and suxamethonium to avoid unpleasant sensation, did not suppress hypertension and increases in heart rate (HR) induced by rapid sequence induction ${ }^{4}$. In the present study effect of pretreatment with magnesium sulphate on suxamethonium induced complications like fasciculation, raised potassium level, myalgia and haemodynamic changes during induction of general anaesthesia were undertaken.

\section{Methods}

After approval of the ethical committee, 60 patients were selected as per inclusion and exclusion criteria. Informed written consent was obtained from each patient. The patients were divided into 2 (two) groups, 30 (thirty) in each group by card sampling. Group-C(control group ) and Group-M(Magnesium sulphate pretreated group). Both the groups received non potassium containing intravenous fluid normal saline $(0.9 \%$ sodium chloride).Preoxygenation performed with $100 \% \mathrm{O}_{2}$ for 5 minutes to all patients. Only group-M received magnesium sulphate $(60 \mathrm{mg}$. $\mathrm{kg}^{-1}$ ) before induction as pretreatment, by intravenous route over 30 seconds. Induction done by using, fentanyl (1mg.kg-1), thiopental sodium (2.5\%) $5 \mathrm{mg} \cdot \mathrm{kg}^{-1}$ followed by suxamethonium 1.5 mg.kg ${ }^{-1}$ Iv. During the period of suxamethonium introduction to intubation only $\mathrm{O}_{2}$ was given through face mask . During this period patient was monitored regarding fasciculations (The degree of muscle fasciculation after administration of suxamethonium was recorded on a scale of 0 to 3 ; no fasciculations $=0$; mild twitches involving face $\&$ fingers only $=1$; fasciculation involving limbs or trunk $=2$; fasciculation producing gross body movement =3). After 60 seconds of giving suxamethonium, tracheal intubation was done. After intubation patient were ventilated manually by Bain system with $\mathrm{O}_{2} 40 \%, \mathrm{~N}_{2} \mathrm{O}-60 \%$, and halothane $0.5 \%$ and anaesthesia maintained by neuromuscular blocking agent vecuronium $\left(0.1 \mathrm{mg} \cdot \mathrm{kg}^{-1}\right)$. Neostigmine $0.04 \mathrm{mg} / \mathrm{kg}$ and atropine $0.02 \mathrm{mg} / \mathrm{kg}$ used as reversal. Pulse, blood pressure $\mathrm{SpO}_{2}$ were recorded pre operatively and at $1^{\text {st }}, 3^{\text {rd }}$, $5^{\text {th }}$, and $7^{\text {th }}$ minutes after intubations; ECG was continuously monitored. Blood sample collected from both group to measure serum potassium concentration before induction and 5 minutes after induction of anaesthesia. In the postoperative room, each patient received inj. pethedine $1.0 \mathrm{mg}$. $\mathrm{kg}^{-1}$ i.m. as initial analgesic then inj. tramadol subsequently. Regarding myalgia, patients were questioned by the investigator about muscle pain at $24^{\text {th }}$ hour after surgery not at the operative site but at their shoulder and neck, trunk and limbs. Data was collected in a prescribed form and analyzed by SPSS (version-15.0). Student's t test, Chi-square test, Fisher's exact test were used to measure level of significance with CL- $95 \%(\mathrm{p}<0.05)$.

\section{Results}

The studied groups became statistically matched for age $(p=0.274)$, weight $(p=0.295)$, sex $(p=0.787)$

Distribution of the patient's fasciculation scale

In table - 1 The difference at different scale of fasciculation between two groups were tested \& found statistically significant $(\mathrm{P}>0.05)$ in no fasciculation $(p=0.001)$ \& fasciculation involving limbs or trunk group $(\mathrm{p}=0.004)$ of fasciculation scale. 
Table I Distribution of the patient's fasciculation

\begin{tabular}{lcccc}
\hline Fasciculation scale & Score & \multicolumn{2}{c}{ Groups } & p value \\
\cline { 3 - 5 } & & & Group-C n=30 & Group-M n=30 \\
\hline No Fasciculation & 0 & $1(3.3)$ & $11(36.7)^{\mathrm{S}}$ & 0.001 \\
Mild twitches involving face \& fingers only & 1 & $11(36.7)$ & $15(50.0)^{\mathrm{NS}}$ & 0.297 \\
Fasciculation involving limbs or trunk & 2 & $13(43.3)$ & $3(10.0)^{\mathrm{S}}$ & 0.004 \\
Fasciculation producing gross body movement & 3 & $5(16.7)$ & $1(3.3)^{\mathrm{NS}}$ & 0.195 \\
\hline
\end{tabular}

Patient's serum potassium concentration at different times

Serum potassium level just before induction was $3.87 \pm 0.13 \mathrm{~m} \mathrm{~mol} / \mathrm{L}$ and 5 minutes after induction was $4.13 \pm 0.27 \mathrm{mmol} / \mathrm{L}$ in group-C. In group-M serum potassium level just before induction was $3.90 \pm 0.13 \mathrm{mmol} / \mathrm{L} \& 3.72 \pm 0.15 \mathrm{mmol} / \mathrm{L} 5$ minutes after induction. The difference of serum potassium in two groups (group-C and group-M) were statistically insignificant $(\mathrm{P}=0.114)$ just before induction; but significantly $(\mathrm{p}=0.001)$ change occurred in two groups.

Table 11 Patient's serum potassium concentration at different times interval.

\begin{tabular}{lccc}
\hline Time interval & \multicolumn{2}{c}{ Groups } & $\mathrm{p}$ \\
\cline { 2 - 3 } & Group C & Group M & value \\
\hline Just before & $3.87 \pm 0.21$ & $3.90 \pm 0.13^{\mathrm{NS}}$ & 0.114 \\
induction & & & \\
5 minutes after & $4.13 \pm 0.27$ & $3.72 \pm 0.15^{\mathrm{S}}$ & 0.001 \\
induction & & & \\
\hline
\end{tabular}

\section{Postoperative myalgia between two groups}

About postoperative myalgia, patients were asked by investigator about muscle pain on their shoulders, neck, trunk and limbs at $24^{\text {th }}$ hours after surgery. 17(56.7) patients in group-C and 9(30) patients in group-M complained about muscle pain which was significant statistically $(\mathrm{p}=0.037)$

Table 111 Postoperative myalgia between two groups

\begin{tabular}{lccc}
\hline Myalgia & \multicolumn{2}{c}{ Groups } & $\mathrm{p}$ \\
\cline { 2 - 4 } & $\begin{array}{c}\text { Group-C } \\
\mathrm{n}=30\end{array}$ & $\begin{array}{c}\text { Group-M } \\
\mathrm{n}=30\end{array}$ & $\begin{array}{c}\text { value } \\
\text { Pain }\end{array}$ \\
\hline
\end{tabular}

Haemodynamic change during induction.

Table IV showed that mean percent change of haemodynamic parameters (pulse, systolic, diastolic and mean blood pressure) observed in two groups just before induction and $1^{\text {st }}$ minute after intubation, less in group-M. Mean percent change between two groups was analyzed by t test to detect any significance and found significant $(p=0.038)$ change in pulse rate, but reduced systolic, diastolic and mean blood pressures in between two groups were insignificant $(\mathrm{p}>0.05)$.

Table IV Mean percent changes between groups

\begin{tabular}{lccc}
\hline $\begin{array}{l}\text { Haemodynamic } \\
\text { parameters }\end{array}$ & \multicolumn{2}{c}{$\begin{array}{c}\text { Mean percent change } \\
\text { from Just before } \\
\text { induction to } 1^{\text {st }} \text { minute }\end{array}$} & $\begin{array}{c}\mathrm{p} \\
\text { value }\end{array}$ \\
\hline Group-C & Group-M & \\
\hline Pulse (bpm) & $17.43 \pm 8.05$ & $12.67 \pm 9.30$ & $0.038^{\mathrm{S}}$ \\
SBP (mmHg) & $7.25 \pm 3.22$ & $5.64 \pm 5.25$ & $0.160^{\mathrm{NS}}$ \\
DBP (mmHg) & $8.84 \pm 5.14$ & $6.63 \pm 5.21$ & $0.103^{\mathrm{NS}}$ \\
MBP (mmHg) & $7.98 \pm 3.86$ & $6.82 \pm 5.89$ & $0.369 \mathrm{NS}$ \\
\hline
\end{tabular}

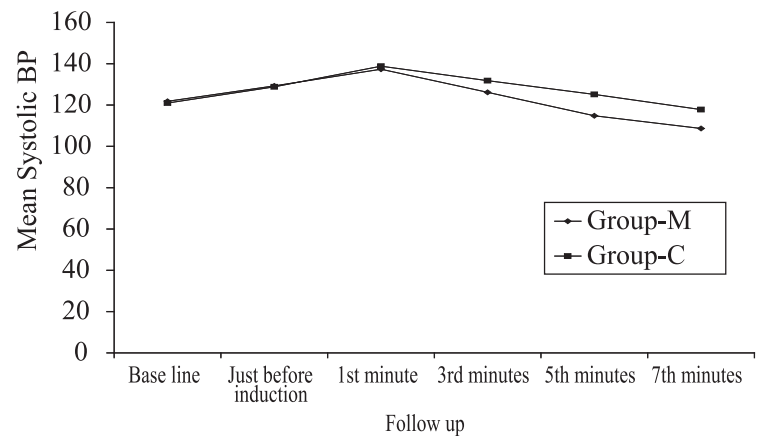

Fig 1 Line chart of the patients' systolic blood pressure at different times

\section{Comparison of side effects in two groups}

Table V showed 1(3.3) patients in group-C and 9 (30) patients in group-M had sweating; 2 (6.7) 
patients in group-C and 5 (16.7) patients in group$\mathrm{M}$ felt palpitation; none in group-C and 9 (30) patients in group-M felt hotness. Sweating was statistically significant ( $\mathrm{p}=0.006)$; palpitation was statistically insignificant $(\mathrm{p}=0.424)$ but hotness was significant (0.002).

Table V Comparison of side effects in two groups

\begin{tabular}{lccc}
\hline Side effect & \multicolumn{2}{c}{ Groups } & $\begin{array}{c}\mathrm{P} \\
\text { value* }\end{array}$ \\
\cline { 2 - 3 } & $\begin{array}{c}\text { Group-C } \\
\mathrm{n}=30\end{array}$ & $\begin{array}{c}\text { Group-M } \\
\mathrm{n}=30\end{array}$ & \\
\hline Sweating & $1(3.3)$ & $9(30.0)$ & $0.006^{\mathrm{S}}$ \\
Palpitation & $2(6.7)$ & $5(16.7)$ & $0.424^{\mathrm{NS}}$ \\
Hotness & $0(.0)$ & $9(30.0)$ & $0.002^{\mathrm{NS}}$ \\
\hline
\end{tabular}

\section{Four point rating score}

In this study fasciculation was significantly reduced in group-M, serum potassium concentration change was significant in between two groups; myalgia was significantly reduced in group-M. haemodynamic changes occurred during intubation; change of pulse rate was significant, change of systolic and mean blood pressure were insignificant in between two groups. So total score 4 out of 6 indicating that magnesium sulphate pretreatment has a role in reducing suxamethonium induced complications during induction of general anaesthesia.

Table Vl Four point rating score in between two groups

\begin{tabular}{|c|c|c|}
\hline \multirow{2}{*}{ Characteristics } & \multicolumn{2}{|c|}{ Score } \\
\hline & $\begin{array}{c}\text { Insignificant } \\
0\end{array}$ & $\begin{array}{c}\text { Significant } \\
1\end{array}$ \\
\hline Reduced fasciculation & & group-M \\
\hline $\begin{array}{l}\text { Change of serum } \mathrm{K}^{+} \\
\text {concentration }\end{array}$ & & group-M \\
\hline Myalgia reduced & & group-M \\
\hline $\begin{array}{l}\text { Haemodynamic change } \\
\text { during intubation Pulse }\end{array}$ & & group-M \\
\hline SBP & group-M & \\
\hline MBP & group-M & \\
\hline
\end{tabular}

\section{Discussion}

Suxamethonium is the gold standard against which all other muscle relaxants are compared due to fast and reliable onset of time. It has some side effects around induction; fasciculation, increased serum potassium concentration and life threatening arrhythmia. It also causes postoperative myalgia. Precurarization with nondepolarizing muscle relaxant is commonly used to limit the complications but not all of them.

In our study no significant difference $(\mathrm{P}>0.05)$ were found in demographic characteristics (age, weight $\&$ sex distribution) between two groups.

Regarding fasciculation, 50\% population scored fasciculation score-2 in group-M in the study of Sakuraba S. et al (2006) ${ }^{5}$. In the study of Stacey MRW et al (1995) ${ }^{4}$ muscle fasciculation occurred in all patients in control group \& only six out of ten patients in magnesium group, which was statistically significant $(\mathrm{P}<0.01)$; fasciculation score3 , that was observed in 3 patients in control group $\& 2$ patients in the magnesium group. Similarly in our study fasciculation score observed higher in group-C. Fasciculation score-3 was observed in $16.7 \%$ population in group-C whereas $3.3 \%$ in group-M. $43.3 \%$ and $10 \%$ population in group-C \& $\mathrm{M}$ respectively scored fasciculation score-2 $(p=0.004)$. Fasciculation score-0 (no fasciculation) occurred in $36.7 \%$ population in group-M and $3.3 \%$ in group-C $(\mathrm{p}=0.001) .50 \%$ patients scored 1 in group-M which was not statistically significant $(p=0.297)$.

In our study, serum potassium concentration just before induction of anaesthesia in between two groups were statistically not significant $(p=0.14)$. Change of serum potassium concentration occurred significantly in between two groups $(p=0.001)$ after 5 minutes of induction of anaesthesia. In the study James MF et al.(1986) showed, in control group potassium level increase in an average of $0.57 \pm$ $0.2 \mathrm{~m} \mathrm{~mol} / \mathrm{L}$; no patient in the magnesium group had an increase in serum potassium (mean change $-0.05 \pm 0.02 \mathrm{mmol} / \mathrm{L}$ ). The difference between the two groups was statistically significant $(\mathrm{P}<0.01)$. Danladi KY et al (2006) ${ }^{9}$ showed that magnesium sulphate pretreatment significantly reduce suxamethonium induced hyperkalaemia by an average of $0.3 \mathrm{mmol} / \mathrm{L}$ which was statistically significant and has similarity with our study. James MF \& Danladi KY both of them used magnesium sulphate (60mg. $\left.\mathrm{kg}^{-1}\right)$ in pretreated group.

Aldrate JA et al (1970) ${ }^{7}$ study showed that in magnesium sulphate $(1 \mathrm{gm})$ pretreated group 
serum calcium \& potassium concentration reduced but there is increase in serum magnesium level after 5 minutes of induction of anaesthesia. Study of Sakuraba S. et al (2006) ${ }^{5}$ and Stacey MRW et al (1995) ${ }^{4}$ failed to establish significant change of serum potassium concentration in two groups. Sakuraba S \& Stacey MRW et al (1995) both of them used magnesium sulphate $40 \mathrm{mg} \cdot \mathrm{kg}^{-1}$ as pretreatment but in our study, we used $60 \mathrm{mg} \cdot \mathrm{kg}^{-1}$ of $\mathrm{MgSO}_{4}$.

In our study myalgia was tested by asking questions at $24^{\text {th }}$ hour after surgery in the postoperative ward and found $30 \%$ population in group-M whereas $56.7 \%$ in group-C complained about muscle pain, which was significantly less $(\mathrm{p}=0.037)$ in group-M. This result has similarity with Aldrate JA study. But Stacey MRW study showed that magnesium sulphate group had no statistically significant reduction of myalgia in correlation with control group. Stacey MRW study differs with our study because they used magnesium sulphate in a dose of $40 \mathrm{mg} \cdot \mathrm{kg}^{-1}$.

Haemodynamic parameters (Pulse, SBP, DBP, and MBP) were evaluated in between just before induction of anaesthesia and $1^{\text {st }}$ minute after intubation. Only mean percent change of pulse rate in between two groups were significant but mean percent change of systolic (SBP), diastolic (DBP) and mean (MBP) blood pressure increased in group$\mathrm{M}$ but lower than group-C. The administration of $\mathrm{MgSO}_{4}$ produces vasodilatation by direct effect on blood vessels and by indirectly sympathetic blockade and inhibition of catecholamine release.

In this study, pulse rate were measured at different times (just before induction of anaesthesia, $1^{\text {st }}, 3^{\text {rd }}, 5^{\text {th }} \& 7^{\text {th }}$ minutes after intubation). There was no significant change of pulse rate between group-M and group-C (control) just before induction $\&$ at $1^{\text {st }} \& 3^{\text {rd }}$ min after intubation but statistically significant reduction occurred in group-M after $5^{\text {th }}$ and $7^{\text {th }}$ minutes of intubation. Yap LC. et al. (1994) 10 study showed that tachycardic response at $1^{\text {st }}$ min after intubation could not be reduced by pretreatment of magnesium sulphate $\left(60 \mathrm{mg} \cdot \mathrm{kg}^{-}\right.$ 1). In our study, it was found that increase in pulse rate was not prevented by magnesium sulphate pretreatment, but significantly reduction of pulse rate occurred in comparison with group-C.
Systolic, diastolic blood pressure \& mean blood pressure were measured at different times in between group-C and group-M. It was found that no statistically significant change occurred just before induction \& $1^{\text {st }}$ minute after intubation but significantly reduced $(\mathrm{P}<0.05)$ in $3^{\text {rd }}, 5^{\text {th }} \& 7^{\text {th }}$ minutes after intubation inbetween two groups. In relation to blood pressure, Yap LC et al (1994) ${ }^{9}$ showed that magnesium sulphate $\left(60 \mathrm{mg} \cdot \mathrm{kg}^{-1}\right)$ could attenuate the hypertensive response at 1 minute following suxamethonium facilitated intubation.

Regarding side effects like sweating, palpitation \& warmness; sweating $(p=0.006)$ and warmness $(\mathrm{p}=0.002)$ were statistically significant in group-M and palpitation $(p=0.424)$ was statistically insignificant. Similarly in the study of Chestnutt W.N. et al (1985) ${ }^{7}$ patients experienced unpleasant warm sensation significantly in $\mathrm{MgSO}_{4}$ pretreated group.

Regarding complications of suxamethonium induced general anaesthesia, with or without pretreatment with $\mathrm{MgSO}_{4}$ a 4 point rating score was done. Total score was 0 to 6 , the more score indicate more effectiveness of magnesium sulphate. In this study score was 4 which was in favor of magnesium sulphate pretreatment in case of reducing suxamethonium induced complications in general anaesthesia. So, our study showed that magnesium sulphate pretreatment has a role in reduction of suxamethonium induced complications in general anaesthesia.

\section{Conclusion}

Under the circumstances from the present study we can conclude that, suxamethonium induced complications like fasciculation, raised serum potassium concentration; haemodynamic change during induction of general anaesthesia and post operative myalgia reduced by pre treatment with magnesium sulphate $60 \mathrm{mg} \cdot \mathrm{kg}^{-1}$.

\section{References}

1. Paton WDM, Waud DR. The margin of safety of neuromuscular transmission . J.Physiol. 1967;191:59-60

2. Kitamuras, Yoshiga I, Tashiro C, Negishi T, Sch causes Fasciculation by prejunctional mecahanism

3. Hodgson RE, Rout CC,Rocke DA, Louw NJ. Mivacurium for caesarean section in 
hypertensive parturients receiving magnesium sulphate therapy. Int $J$ Obstet Anesth 1998;7(1):12-7

4. Stacey MRW, K. Braclay, T.Asai and R.S.Vaughan. Effecrs of magnesium sulphate on suxamethonium-induced complications during rapid sequence inductionof anaesthesia. Anaesthesia 1995; 50: 933

5. Sakuraba S, Serita R, Kosugi S, Eriksson LI, Lindahl SG, Takeda J Pretreatment with magnesium sulphate is associated with less succinylcholine-induced fasciculation and subsequent tracheal intubation-induced hemodynamic changes than precurarization with vecuronium during rapid sequence induction. Acta Anaesthesiol Belg 2006; 57(3):253-7.

6. Stoelting RK, Petersen C. Adverse effects of increased Succinylcholine dose following d- tubocurarine pretreatment. Anaesth Analg $1975 ; 54: 282-8$

7. Aldrate JA, Zahler A, Aikawa JK. Prevention of succinylcholine-induced hyperkalemia by magnesium sulfate. Can Anaesth Soc J 1970;17:477-84

8. Chestnutt WN, Dundee JW. Failure of magnesium sulphate to prevent suxamethonium induced muscle pains, Anaesthesia., 1985;40:488-90,1985

9. Danladi KY, Sotunmbi PT, Eyelade OR. The effects of magnesium sulphate-pretreatment on suxamethonium-induced complications during induction of general endotrachel anaesthesia. Afr J Med Med Sci. 2007; 36 (1): 43-7

10. Yap LC, Ho RT, Jawan B, Lee JH. Effects of magnesium sulfate pretreatment on succinylcholine-facilitated tracheal intubation. Acta Anaesthesiol Sin 1994; 32: 45-50 